\title{
Organotellurium-mediated living radical polymerization under photoirradiation by a low-intensity light-emitting diode
}

Yasuyuki Nakamura and Shigeru Yamago*

\author{
Full Research Paper \\ Address: \\ Institute for Chemical Research, Kyoto University, Gokasyo, Uji, Kyoto \\ 611-0011, Japan, and Core Research for Evolutional Science and \\ Technology (CREST), Japan Science and Technology Agency (JST) \\ Email: \\ Shigeru Yamago* - yamago@scl.kyoto-u.ac.jp \\ * Corresponding author \\ Keywords: \\ free radical; light-emitting diode; living radical polymerization; \\ organotellurium compound; photopolymerization; tellurium; visible \\ light
}

Open Access

Beilstein J. Org. Chem. 2013, 9, 1607-1612.

doi:10.3762/bjoc. 9.183

Received: 05 June 2013

Accepted: 12 July 2013

Published: 07 August 2013

This article is part of the Thematic Series "Organic free radical chemistry".

Guest Editor: C. Stephenson

(ㄷ) 2013 Nakamura and Yamago; licensee Beilstein-Institut. License and terms: see end of document.

\begin{abstract}
A low-intensity $(6 \mathrm{~W})$ light-emitting diode (LED) effectively activated an organotellurium chain transfer agent and the dormant species, promoting well-controlled radical polymerization. The use of the LED provided many advantages over the previously reported high-intensity Hg lamp, including high energy efficiency during the polymerization, and easy availability of the low-cost light source. Structurally well-defined poly(methyl methacrylate), poly(methyl acrylate), and polystyrene, with narrow molecular weight distributions, were synthesized under LED irradiation with or without a neutral density filter.
\end{abstract}

\section{Introduction}

Living radical polymerization (LRP) is one of the most powerful methods for the synthesis of structurally well-defined polymers because of its robustness and high versatility, which allows for the polymerization of a wide variety of vinyl monomers with various functionalities [1-3]. LRP relies on the reversible generation of polymer-end radicals from a dormant species. One approach to the activation of the dormant species is the use of photostimulation. This has been widely employed in conventional radical polymerization for various applications such as coatings, adhesives, gels and microelectronics [4-7]. The major motivation for the utilization of photochemistry in LRP is that it enables the dormant species to be activated under mild thermal conditions [8-11]. In addition, photochemical activation is beneficial for increasing the fidelity of the polymerend structure [12]. However, the experimental setup required for the reaction provides problems, as distinctive light sources such as $\gamma$-rays or high-intensity UV irradiation are required [1321].

We have previously developed organotellurium-mediated LRP (TERP), which has several synthetic advantages over other LRP methods [22-24]. These include high monomer versatility [2527], good compatibility with polar functional groups and solvents $[28,29]$, and facile living-end transformation for the 
synthesis of block copolymers [30-34] and end-functional polymers $[35,36]$. Furthermore, we recently reported that photochemical stimuli were efficient in the activation of organotellurium dormant species, and that TERP proceeded under mild thermal conditions to give highly controlled polymers [37]. The polymerization proceeded by irradiation with a weak-intensity light source such as a $60-100 \mathrm{~W}$ black lamp or sunlight, but we routinely used a high-intensity light source, namely, a $500 \mathrm{~W}$ high pressure Hg lamp, combined with a light cutoff filter. However, control of the light intensity was difficult under such conditions. For example, when light of a relatively high intensity was used to prepare a polyisoprene using TERP, a radical coupling reaction occurred because of the efficient formation of the polymer-end radical [38]. In addition, when ditellurides were added to the TERP reaction in order to increase the level of control over the polymerization of methacrylates, optimization of the conditions was difficult, because ditellurides have a stronger absorption coefficient than the organotellurium compounds (Figure 1). This resulted in the generation of tellurium radicals, which activate the organotellurium dormant species [30,39]. Therefore, the development of new photochemical conditions which employ a weak-intensity, readily available light source is necessary for expanding the utility of photoTERP. We focused on a light emitting diode (LED) due to its high power conversion efficiency, low heat generation, narrow and tunable wavelength range of the emitted light, and ease of availability. Herein, we report on the use of photo-TERP with a $6 \mathrm{~W}$ white, household LED (Scheme 1). Attention was focused on the TERP of methyl methacrylate (MMA) in the presence of ditelluride, but other typical conjugated monomers, namely, methyl acrylate and styrene, were also evaluated. TERP of these monomers proceeded efficiently in a controlled manner by adjusting the light intensity using ND filters. The results clearly demonstrate the extremely high sensitivity of organotellurium compounds for generating radical species by photostimulation.

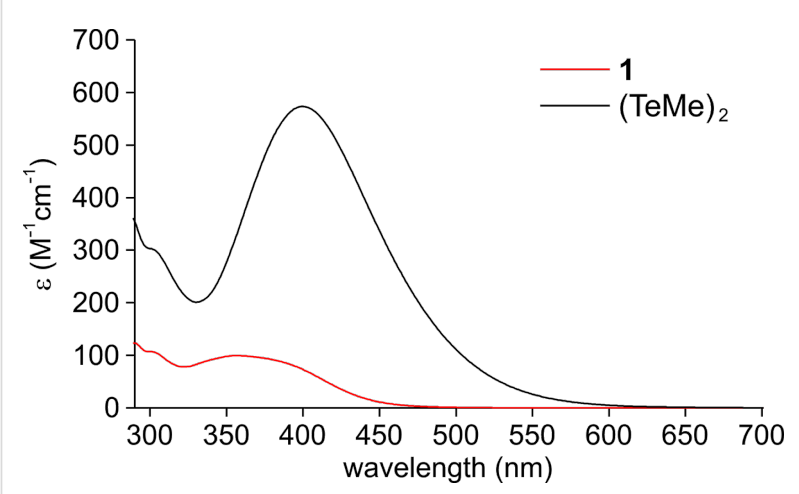

Figure 1: UV-vis absorption spectra of organotellurium chain transfer agent 1 and dimethyl ditelluride in toluene.

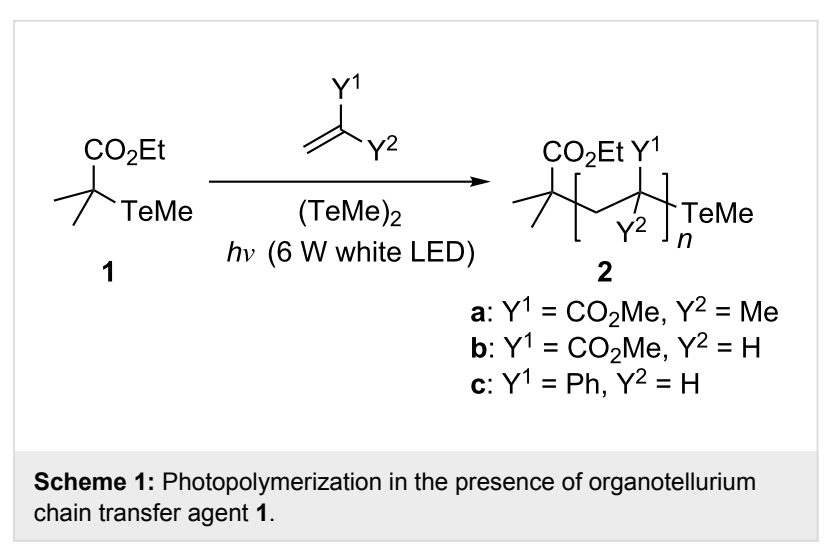

Based on these findings, we also adjust our previous statements regarding the effect of ditelluride on TERP.

\section{Results and Discussion}

The polymerization of MMA (100 equiv) was first conducted in the presence of organotellurium chain transfer agent 1 ( 1 equiv) and dimethyl ditelluride (1 equiv) under $6 \mathrm{~W}$ white LED at $70{ }^{\circ} \mathrm{C}$ (Scheme 1 and Table 1, run 1). The polymerization progressed rapidly, reaching $93 \%$ monomer conversion after $1 \mathrm{~h}$. However, the number-average molecular weight $\left(M_{\mathrm{n}}\right)$ of the resulting polymer $\left(\mathbf{2 a}, M_{\mathrm{n}(\exp )}=11900\right)$ deviated slightly from the theoretical value, as calculated from the monomer/1 ratio and the monomer conversion $\left(M_{\mathrm{n}(\text { theo })}=9400\right)$. In addition, the control of molecular weight distribution (MWD, $M_{\mathrm{W}} / M_{\mathrm{n}}=1.26 ; M_{\mathrm{w}}$ refers to weight average molecular weight) was moderate.

We have previously reported that the intensity of irradiating light is critical for gaining control of the polymerization [37]. Therefore, we investigated the effect of the light intensity by using ND filters (Figure 2). When a 50\% transmittance ND filter was used, the MWD improved to 1.20 from 1.26, while $2 \mathrm{~h}$ was required to reach $>90 \%$ monomer conversion (Table 1 , run 2). The MWD control was further improved when the light intensity was reduced by using $30 \%$ and $20 \%$ transmittance ND filters $\left(M_{\mathrm{w}} / M_{\mathrm{n}}=1.18-1.19\right)$, although the monomer conversion further slowed down with this order (Table 1, runs 3 and 4). The MWD control reached a plateau when a $10 \%$ transmittance ND filter was used, while the polymerization rate was further decelerated (Table 1, run 5). In the absence of light irradiation, the polymerization was extremely slow, reaching only $36 \%$ monomer conversion, even after $12 \mathrm{~h}$ (Table 1, run 6). These results clearly demonstrate that weak light intensity was sufficient for activating the organotellurium compounds. The concentration of the radical species was roughly proportional to the light intensity. The monomer conversion after $1 \mathrm{~h}$ increased nearly linearly by the use of ND filters with higher transmittance ( 25 , $36,47,62$, and $93 \%$ monomer conversion by using $10,20,30$, 
Table 1: Photopolymerization of MMA in the presence of 1 under LED irradiation. ${ }^{\text {a }}$

\begin{tabular}{|c|c|c|c|c|c|c|c|}
\hline Run & MMA/1 ratio & ND filter ${ }^{b}$ & Time $(\mathrm{h})$ & Conv. $(\%)^{\mathrm{c}}$ & $M_{\mathrm{n} \text { (theo) }}$ & $M_{\mathrm{n}(\exp )^{\mathrm{d}}}$ & $M_{\mathrm{w}} / M_{\mathrm{n}}{ }^{\mathrm{d}}$ \\
\hline 1 & 100 & none & 1.0 & 93 & 9400 & 11900 & 1.26 \\
\hline 2 & 100 & 50 & 2.0 & 92 & 9300 & 10700 & 1.20 \\
\hline 3 & 100 & 30 & 2.5 & 93 & 9400 & 9800 & 1.19 \\
\hline 4 & 100 & 20 & 4.0 & 92 & 9300 & 9500 & 1.18 \\
\hline 5 & 100 & 10 & 5.5 & 93 & 9500 & 10400 & 1.18 \\
\hline $6^{e}$ & 100 & none & 12 & 36 & 3700 & 2500 & 1.27 \\
\hline $7^{f}$ & 100 & 20 & 6.0 & 94 & 9500 & 10400 & 1.18 \\
\hline $8^{9}$ & 100 & 20 & 3.0 & 91 & 9200 & 9600 & 1.19 \\
\hline $9^{h}$ & 100 & 20 & 2.5 & 93 & 9400 & 9900 & 1.19 \\
\hline 10 & 200 & 20 & 4.0 & 92 & 18500 & 20500 & 1.17 \\
\hline 11 & 300 & 20 & 4.5 & 94 & 28400 & 31900 & 1.14 \\
\hline $12^{i}$ & 500 & 10 & 5.0 & 94 & 47200 & 52400 & 1.14 \\
\hline $13^{i}$ & 1000 & 10 & 5.5 & 91 & 91200 & 109700 & 1.25 \\
\hline
\end{tabular}

aA solution of 1 , dimethyl ditelluride (1 equiv) and monomer (100 equiv) was irradiated with a 6 W LED with or without a ND filter at $70{ }^{\circ} \mathrm{C}$. b\% Transmittance is shown. ${ }^{c}$ Determined by ${ }^{1} \mathrm{H}$ NMR. ${ }^{d}$ Determined by GPC calibrated with PMMA standards. ${ }^{\mathrm{e}}$ The reaction was carried out in the dark. ${ }^{\mathrm{f}}$ The polymerization was carried out at $60{ }^{\circ} \mathrm{C}$. ${ }^{9}$ The polymerization was carried out at $80^{\circ} \mathrm{C}$. h ${ }^{\mathrm{T}}$ The polymerization was carried out at $90{ }^{\circ} \mathrm{C}$. 2 equiv of dimethyl ditelluride was used.

$50 \%$ ND filter and direct irradiation, respectively). The poor MWD control under high-intensity light is probably due to the increase in undesired termination reactions of the polymer-end radicals. When the termination is negligible, the level of MWD control is determined by the rate of deactivation of the polymerend radicals by ditelluride forming a dormant species [39] which is independent of the light intensity.

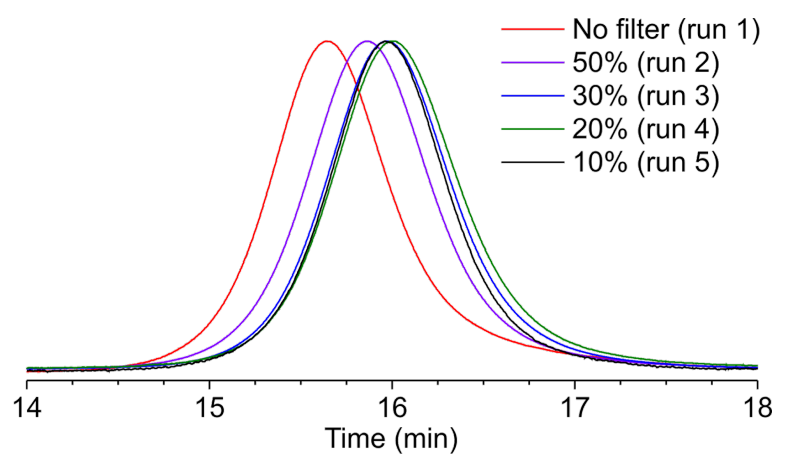

Figure 2: GPC traces for the polymerizations of MMA (Table 1). The percentages in the legend refer to the ND filters used.

The synthetic scope of MMA polymerization was next examined (Table 1, runs 7-13). As the generation of the polymer-end radical from the organotellurium dormant species does not require thermal stimuli, the reaction temperature can be arbitrarily selected depending on the propagation rate of the particular monomer. For example, the same polymerization proceeded over the range of $60-90{ }^{\circ} \mathrm{C}$ under otherwise identical conditions, affording structurally well controlled PMMAs in all cases
(Table 1, runs 7-9). The conversion of the monomer was slow at lower temperatures because of the decrease in propagation rate, but the MWDs were identical in all cases, within the experimental error. Due to the high propagation rate at high temperatures the polymerization at $90{ }^{\circ} \mathrm{C}$ reached $>90 \%$ monomer conversion within $2.5 \mathrm{~h}$, affording PMMA with a narrow $\operatorname{MWD}\left(M_{\mathrm{w}} / M_{\mathrm{n}}=1.19\right.$, Table 1 , run 9).

Structurally well controlled, high-molecular-weight PMMAs were also prepared by changing the monomer/ $\mathbf{1}$ ratio (Table 1 , runs 10-13). When 200-1000 equivalents of MMA over 1 were employed, monomer conversion reached $>90 \%$ in all cases within $5.5 \mathrm{~h}$, and PMMAs with a $M_{\mathrm{n}}$, of 20500-109700 with a narrow MWD $\left(M_{\mathrm{W}} / M_{\mathrm{n}} \leq 1.25\right)$ were synthesized. When more than 500 equivalents of monomer were employed, the addition of two equivalents of dimethyl ditelluride, as well as the use of a $10 \%$ transmittance ND filter, resulted in improved MWDs (Table 1, runs 12 and 13).

The use of the LED was also found to be effective for the efficient and controlled polymerization of other monomers (Table 2). For example, TERP of methyl acrylate (100 equiv) without ditelluride reached $91 \%$ monomer conversion after $1.6 \mathrm{~h}$ irradiation with the LED without an ND filter at $50{ }^{\circ} \mathrm{C}$. Structurally well-defined poly(methyl acrylate) (PMA) with $M_{\mathrm{n}}=10100$ and a narrow MWD $\left(M_{\mathrm{w}} / M_{\mathrm{n}}=1.11\right)$ was obtained (Table 2, run 1). High-molecular-weight PMAs with narrow MWDs $\left(M_{\mathrm{n}}=90200, M_{\mathrm{w}} / M_{\mathrm{n}}=1.13\right.$ and $M_{\mathrm{n}}=166000$, $\left.M_{\mathrm{w}} / M_{\mathrm{n}}=1.15\right)$ were also prepared by changing the monomer $/ \mathbf{1}$ ratio under LED irradiation through a $50 \%$ transmittance ND filter (Table 2, runs 2 and 3). 


\begin{tabular}{|c|c|c|c|c|c|c|c|c|}
\hline Run & $\begin{array}{r}\text { Monomer } \\
\text { (equiv) }^{\mathrm{b}}\end{array}$ & $\begin{array}{r}\mathrm{ND} \text { filter } \\
\text { (\% transmittance) }\end{array}$ & Temp. $\left({ }^{\circ} \mathrm{C}\right)$ & Time (h) & Conv. $(\%)^{c}$ & $M_{\mathrm{n} \text { (theo) }}$ & $M_{\mathrm{n}(\exp )^{\mathrm{d}}}$ & $M_{\mathrm{w}} / M_{\mathrm{n}}^{\mathrm{d}}$ \\
\hline 1 & MA (100) & none & 50 & 1.6 & 91 & 8000 & 10100 & 1.11 \\
\hline 2 & MA (1000) & 50 & 50 & 5 & 93 & 80100 & 90200 & 1.13 \\
\hline 3 & MA (2000) & 50 & 50 & 8 & 86 & 148100 & 166000 & 1.15 \\
\hline 4 & St (100) & none & 90 & 6 & 96 & 10100 & 18200 & 1.36 \\
\hline 5 & St (100) & 20 & 90 & 9 & 98 & 10300 & 11600 & 1.09 \\
\hline 6 & St (500) & 10 & 90 & 14 & 95 & 49500 & 47400 & 1.18 \\
\hline 7 & St (1000) & 10 & 90 & 16 & 83 & 86500 & 87500 & 1.33 \\
\hline
\end{tabular}

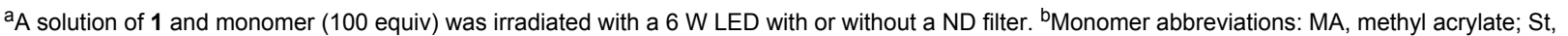
styrene. ${ }^{\mathrm{C}}$ Determined by ${ }^{1} \mathrm{H}$ NMR. ${ }^{\mathrm{d}}$ Determined by GPC calibrated with PMMA or polystyrene standards.

Next, the polymerization of styrene was examined at $90{ }^{\circ} \mathrm{C}$, as the propagation rate constant of styrene is much lower than those of acrylates and methacrylates. Polymerization in the absence of a filter quantitatively converted the monomer to the polymer within $6 \mathrm{~h}(96 \%)$, but the $M_{\mathrm{n}(\exp )}$ of the resulting polystyrene (18100) was significantly different from the $M_{\mathrm{n} \text { (theo) }}$ (10100), and the MWD control was unsatisfactory $\left(M_{\mathrm{w}} / M_{\mathrm{n}}=\right.$ 1.36) (Table 2, run 4). On the other hand, when the polymerization was carried out through a $20 \%$ transmittance ND filter, although the monomer conversion was slower, the resulting polystyrene had a $M_{\mathrm{n}(\exp )}$ close to $M_{\mathrm{n} \text { (theo), and a very narrow }}$ $\operatorname{MWD}\left(M_{\mathrm{W}} / M_{\mathrm{n}}=1.09\right)$ (Table 2, run 5). High-molecular-weight polystyrene of $M_{\mathrm{n}}=47400$ and 87500 , with narrow MWDs $\left(M_{\mathrm{W}} / M_{\mathrm{n}}=1.18\right.$ and 1.33 , respectively) were successfully synthesized by using a $10 \%$ transmittance ND filter (Table 2 , runs 6 and 7).

When the ditelluride is absent, polymerization is initiated by the direct photolysis of the carbon-tellurium bond of the organotellurium dormant species, $\mathrm{P}-\mathrm{TeMe}$ (Scheme 2, reaction 1, $\mathrm{P}$ denotes polymer) [37]. Once the polymer radical is generated, it predominantly undergoes a degenerative chain transfer-mediated polymerization reaction (Scheme 2, reaction $2, \mathrm{P}^{\prime}$ refers to a polymer with either the same or different chain length as $\mathrm{P}$ ) $[25,40]$. When the ditelluride is present, its activation produces two molecules of methyltellanyl radical (Scheme 2, reaction 3). As ditelluride possesses a higher absorption coefficient in the UV region than organotellurium compounds such as $\mathbf{1}$ (Figure 1), the preferential activation of ditelluride over organotellurium compounds should occur. Once a methyltellanyl radical forms, it activates $\mathrm{P}-\mathrm{TeMe}$, giving a polymer endradical and a ditelluride (Scheme 2, reaction 4).

We have previously reported that the addition of ditelluride accelerates the TERP and that the activation of $\mathrm{P}-\mathrm{TeMe}$ by a methyltellanyl radical is the origin of this rate enhancement [39]. However, the mechanism by which this occurs has not

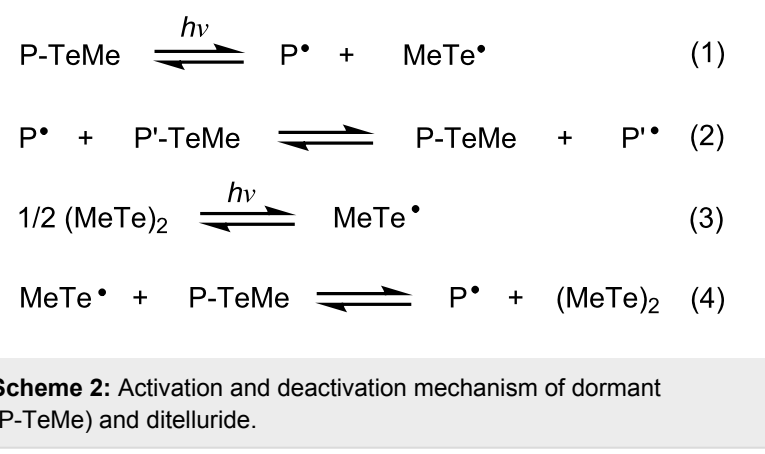

been fully elucidated. As we have deduced that the activation of ditelluride successfully proceeds under very weak intensity light irradiation, the tellanyl radical should also be formed by the photons from interior fluorescent lighting. Indeed, TERP of MMA in the presence of ditelluride completed in approximately $13 \mathrm{~h}$ at $80^{\circ} \mathrm{C}$, without any special caution under interior fluorescent lighting [30], whereas the same experiment completely protected from all light sources took $22 \mathrm{~h}$.

\section{Conclusion}

A new and efficient procedure for photoinduced TERP was developed by using a low energy (6 W) visible LED as the light source. Compared to previously employed photoinduced TERP by using a $60-500 \mathrm{~W}$ light source, the energy efficiency was significantly improved. As the TERP of MMA and styrene was best controlled in combination with 10 or $20 \%$ transmittance ND filters, light with an intensity below $6 \mathrm{~W}$ should also be usable. Improvement in the MWD could be achieved by appropriate tuning of the light intensity. As activation of the organotellurium compounds has been shown to be possible with a low power and readily available LED, implementation to large scale synthesis should be feasible. Furthermore, the activation of the dormant species does not require thermal stimuli, and so independent control of the initiation (radical generation) and the propagation should be possible. 


\section{Experimental}

General: All reactions involving oxygen and moisture sensitive compounds were carried out in a dry reaction vessel under a nitrogen atmosphere. A $6 \mathrm{~W}$ white LED (Panasonic) was used as the light source in combination with a neutral density (ND) filter (Sigma Koki). ${ }^{1} \mathrm{H}$ NMR (400 MHz) spectra were measured for a $\mathrm{CDCl}_{3}$ solution of the sample and are reported in ppm ( $\delta$ ) from an internal of tetramethylsilane. Gel permeation chromatography (GPC) was performed on a machine equipped with two linearly connected polystyrene mixed gel columns (Shodex LF-604) at $40{ }^{\circ} \mathrm{C}$ by using UV and refluctive index (RI) detectors with chloroform as the eluent. The numberaverage molecular weight $\left(M_{\mathrm{n}}\right)$ is reported in $\mathrm{g} \cdot \mathrm{mol}^{-1}$. PMMA and poly(methyl acrylate) were calibrated with PMMA standards, and polystyrene was calibrated with polystyrene standards.

Materials: Unless otherwise noted, chemicals obtained from commercial suppliers were used as received. Methyl methacrylate (MMA), methyl acrylate and styrene were washed with 5\% $\mathrm{NaOH}$ aqueous solution and were distilled over $\mathrm{CaH}_{2}$. Ethyl 2-methyltellanylisobutylate (1) and dimethyl ditelluride were prepared as reported [22]. The UV-vis spectra of $\mathbf{1}$ and dimethyl ditelluride are shown in Figure 1.

Typical procedure for photopolymerization: A solution of MMA (1.0 mL, $9.4 \mathrm{mmol}), 1$ (16.5 $\mu \mathrm{L}, 0.094 \mathrm{mmol})$, and dimethyl ditelluride $(10.0 \mu \mathrm{L}, 0.094 \mathrm{mmol})$ was irradiated with a $6 \mathrm{~W}$ white LED equipped with a $20 \% \mathrm{ND}$ filter at $70{ }^{\circ} \mathrm{C}$ for $4 \mathrm{~h}$ under a nitrogen atmosphere in a capped tube (Figure 3 ). A

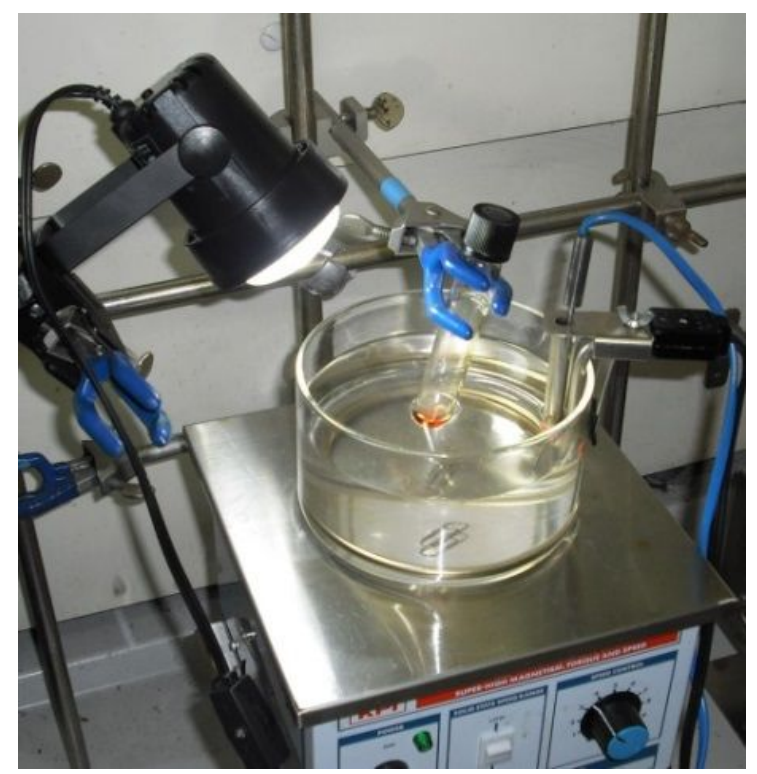

Figure 3: Experimental setup for the photopolymerization using the LED. small portion of the reaction mixture was then removed, and the conversion of the monomer (92\%) was determined by using ${ }^{1} \mathrm{H}$ NMR spectroscopy. The reaction mixture was analyzed by using GPC, and the $M_{\mathrm{n}}(9500)$ and $M_{\mathrm{w}} / M_{\mathrm{n}}(1.18)$ were determined. Chloroform was subsequently added to the mixture, and the resulting solution was poured into hexane with vigorous stirring. The product was collected by suction filtration and dried under vacuum to give the final PMMA product $(810 \mathrm{mg})$.

\section{References}

1. Matyjaszewski, K.; Davis, T. P. Handbook of Radical Polymerization; John Wiley and Sons: Hoboken, 2002.

2. Matyjaszewski, K.; Moeller, M.; Sawamoto, M.; Coates, G. W., Eds. Chain Polymerization of Vinyl Monomers; Polymer Science: A Comprehensive Reference, Vol. 3; Elsevier BV: Amsterdam, 2012.

3. Polymers and Materials; Chatgilialoglu, C.; Studer, A., Eds.; Encyclopedia of Radicals in Chemistry, Biology and Materials; John Wiley and Sons, 2012.

4. Fouassier, J.-P. Photoinitiation, Photopolymerization, and Photocuring: Fundamentals and Applications; Hanser-Gardner Publications: Munich, 1995.

5. Tasdelen, M. A.; Yagci, Y. Aust. J. Chem. 2011, 64, 982-991. doi:10.1071/CH11113

6. Yamago, S.; Nakamura, Y. Polymer 2013, 54, 981-994. doi:10.1016/j.polymer.2012.11.046

7. Tasdelen, M. A.; Çiftci, M.; Uygun, M.; Yagci, Y. Progress in controlled radical polymerization: materials and applications. Matyjaszewski, K.; Sumerlin, B. S.; Tsarevsky, N. V., Eds.; American Chemical Society: Washington DC, 2012; p 59.

8. Konkolewicz, D.; Schröder, K.; Buback, J.; Bernhard, S.; Matyjaszewski, K. ACS Macro Lett. 2012, 1, 1219-1223. doi:10.1021/mz300457e

9. Fors, B. P.; Hawker, C. J. Angew. Chem., Int. Ed. 2012, 51, 8850-8853. doi:10.1002/anie.201203639

10. Ohtsuki, A.; Goto, A.; Kaji, H. Macromolecules 2013, 46, 96-102. doi:10.1021/ma302244j

11. Zhao, Y.; Yu, M.; Fu, X. Chem. Commun. 2013, 49, 5186-5188. doi:10.1039/c3cc41466c

12. Nakamura, Y.; Kitada, Y.; Kobayashi, Y.; Ray, B.; Yamago, S. Macromolecules 2011, 44, 8388-8397. doi:10.1021/ma201761q

13. Bai, R.-K.; You, Y.-Z.; Pan, C.-Y. Macromol. Rapid Commun. 2001, 22, 315-319.

doi:10.1002/1521-3927(20010301)22:5<315::AID-MARC315>3.0.CO;2 $-\mathrm{O}$

14. Quinn, J. F.; Barner, L.; Davis, T. P.; Thang, S. H.; Rizzardo, E. Macromol. Rapid Commun. 2002, 23, 717-721. doi:10.1002/1521-3927(20020801)23:12<717::AID-MARC717>3.0.CO; 2-I

15. Barner, L.; Quinn, J.; Barner-Kowollik, C.; Vana, P.; Davis, T. P. Eur. Polym. J. 2003, 39, 449-459. doi:10.1016/S0014-3057(02)00247-1

16. Millard, P.-E.; Barner, L.; Stenzel, M. H.; Davis, T. P.; Barner-Kowollik, C.; Müller, A. H. E. Macromol. Rapid Commun. 2006, 27, 821-828. doi:10.1002/marc.200600115

17. Chen, G.; Zhu, X.; Zhu, J.; Cheng, Z. Macromol. Rapid Commun. 2004, 25, 818-824. doi:10.1002/marc.200300266

18. Quinn, J. F.; Barner, L.; Barner-Kowollik, C.; Rizzardo, E.; Davis, T. P. Macromolecules 2002, 35, 7620-7627. doi:10.1021/ma0204296 
19. Lu, L.; Yang, N.; Cai, Y. Chem. Commun. 2005, 5287-5288. doi:10.1039/b512057h

20. Muthukrishnan, S.; Pan, E. H.; Stenzel, M. H.; Barner-Kowollik, C.; Davis, T. P.; Lewis, D.; Barner, L. Macromolecules 2007, 40, 2978-2980. doi:10.1021/ma0703094

21. Tasdelen, M. A.; Durmaz, Y. Y.; Karagoz, B.; Bicak, N.; Yagci, Y. J. Polym. Sci., Part A: Polym. Chem. 2008, 46, 3387-3395. doi:10.1002/pola.22686

22. Yamago, S.; lida, K.; Yoshida, J. J. Am. Chem. Soc. 2002, 124, 2874-2875. doi:10.1021/ja025554b

23. Yamago, S. Chem. Rev. 2009, 109, 5051-5068. doi:10.1021/cr9001269

24. Yamago, S.; Nakamura, Y. Other Degenerative Transfer Systems. In Chain Polymerization of Vinyl Monomers; Matyjaszewski, K.; Möller, M., Eds.; Polymer Science: A Comprehensive Reference, Vol. 3; Elsevier BV: Amsterdam, 2012; pp 227-247. doi:10.1016/B978-0-444-53349-4.00067-4

25. Goto, A.; Kwak, Y.; Fukuda, T.; Yamago, S.; lida, K.; Nakajima, M.; Yoshida, J. J. Am. Chem. Soc. 2003, 125, 8720-8721. doi:10.1021/ja035464m

26. Mishima, E.; Tamura, T.; Yamago, S. Macromolecules 2012, 45 , 8998-9003. doi:10.1021/ma301570r

27. Mishima, E.; Tamura, T.; Yamago, S. Macromolecules 2012, 45, 2989-2994. doi:10.1021/ma300325r

28. Mishima, E.; Yamago, S. Macromol. Rapid Commun. 2011, 32, 893-898. doi:10.1002/marc.201100089

29. Sugihara, Y.; Kagawa, Y.; Yamago, S.; Okubo, M. Macromolecules 2007, 40, 9208-9211. doi:10.1021/ma071363n

30. Yamago, S.; lida, K.; Yoshida, J. J. Am. Chem. Soc. 2002, 24, 13666-13667. doi:10.1021/ja027599i

31. Ray, B.; Kotani, M.; Yamago, S. Macromolecules 2006, 39, 5259-5265. doi:10.1021/ma060248u

32. Yusa, S.; Yamago, S.; Sugahara, M.; Morikawa, S.; Yamamoto, T.; Morishima, Y. Macromolecules 2007, 40, 5907-5915. doi:10.1021/ma070769x

33. Kumar, S.; Changez, M.; Murthy, C. N.; Yamago, S.; Lee, J.-S. Macromol. Rapid Commun. 2011, 32, 1576-1582. doi:10.1002/marc.201100277

34. Mishima, E.; Yamada, T.; Watanabe, H.; Yamago, S. Chem.-Asian J. 2011, 6, 445-451. doi:10.1002/asia.201000402

35. Yamada, T.; Mishima, E.; Ueki, K.; Yamago, S. Chem. Lett. 2008, 37 650-651. doi:10.1246/cl.2008.650

36. Yamago, S.; Kayahara, E.; Yamada, H. React. Funct. Polym. 2009, 69, 416-423. doi:10.1016/j.reactfunctpolym.2009.03.008

37. Yamago, S.; Ukai, Y.; Matsumoto, A.; Nakamura, Y. J. Am. Chem. Soc. 2009, 131, 2100-2101. doi:10.1021/ja8099689

38. Nakamura, Y.; Arima, T.; Tomita, S.; Yamago, S. J. Am. Chem. Soc. 2012, 134, 5536-5539. doi:10.1021/ja300869x

39. Kwak, Y.; Tezuka, M.; Goto, A.; Fukuda, T.; Yamago, S. Macromolecules 2007, 40, 1881-1885. doi:10.1021/ma0623385

40. Kwak, Y.; Goto, A.; Fukuda, T.; Kobayashi, Y.; Yamago, S. Macromolecules 2006, 39, 4671-4679. doi:10.1021/ma060295m

\section{License and Terms}

This is an Open Access article under the terms of the Creative Commons Attribution License

(http://creativecommons.org/licenses/by/2.0), which permits unrestricted use, distribution, and reproduction in any medium, provided the original work is properly cited.

The license is subject to the Beilstein Journal of Organic Chemistry terms and conditions:

(http://www.beilstein-journals.org/bjoc)

The definitive version of this article is the electronic one which can be found at:

doi:10.3762/bjoc. 9.183 